\title{
EDITORIAL NOTE Global climate change and dengue
}

Perhaps one of the most discussed scientific issues regarding the environment nowadays is global climate change. Numerous scientists around the world are putting in tremendous efforts trying to understand several aspects of this worldwide phenomenon that will affect human life on this planet. Actually, various studies point out that the effects of climate change can already be felt in some areas and are starting to concern many governments.

Among the original papers that are being published in this issue of the Anais da Academia Brasileira de Ciências (AABC), one touches on this topic. David M. Lapola and colleagues of the Instituto Nacional de Pesquisas Espaciais and Divisão de Ciências Atmosféricas are providing a new world natural vegetation map. As already recognized, vegetation plays an essential role regarding global climate regulation. However, there are regional discrepancies among the few global natural vegetation maps available which are minimized in this contribution. During the process of their studies, Lapola and colleagues have introduced a new biome, named tropical seasonal forest, which is defined in their paper. The results will be useful in global change studies.

Still regarding climate, in another contribution published in the present issue of the AABC, Mauro B. de Toledo of the Universidade Federal Fluminense and Mark B. Bush of the Florida Institute of Technology have provided new information regarding how climate and human activities may have influenced the range of savannas within the Brazilian Amazonia. Those authors have focused their study in a sediment core raised from the middle of the Márcio lake, situated in Amapá. This region is located about $10 \mathrm{~km}$ from the Amazon River and is presently inhabited by a community of former slaves that established small settlements starting in the XVIII century. Toledo and Bush analyzed the core samples for "fossil" pollen and charcoal records and were able to determine an abrupt change of vegetation surrounding the lake about 5000 years ago. Furthermore, they show that approximately at that time a great impact on the environment occurred, which might have been caused by a combination of factors, including human occupation.

There is another paper of this issue of the AABC that provides information about a current problem that is being intensively discussed in the Brazilian society: dengue. Particularly in Rio de Janeiro, this human pathogen that is transmitted by infected mosquitoes is of great concern, taking epidemic proportions, apparently spreading to other regions of the country. Gisela F. Trindade and colleagues from the Fundação Oswaldo Cruz have studied the replication of some flaviviruses - including dengue viruses, in rhesus monkeys. Their results might be another step contributing to the development of vaccines against dengue and other related diseases.

Alexander W.A. Kellner

Editor-in-chief 